EXTENDED REPORT

\title{
Decrease of anti-cyclic citrullinated peptide antibodies and rheumatoid factor following anti-TNF $\alpha$ therapy (infliximab) in rheumatoid arthritis is associated with clinical improvement
}

\author{
C Alessandri, M Bombardieri, N Papa, M Cinquini, L Magrini, A Tincani, G Valesini
}

Ann Rheum Dis 2004;63:1218-1221. doi: 10.1136/ard.2003.014647

See end of article for authors' affiliations

Correspondence to:

Professor G Valesini, Dipartimento di Clinica e Terapia Medica Applicata, Cattedra di Reumatologia, Università "La Sapienza", $V^{\prime}$ le del Policlinico 155 00161 Rome, Italy; guido.valesini@ uniromal.it

Accepted

19 November 2003

\begin{abstract}
Objective: To investigate the effect of infliximab treatment on anti-cyclic citrullinated peptide antibodies (anti-CCP) and rheumatoid factor (RF) in patients with rheumatoid arthritis.

Methods: 43 patients with rheumatoid arthritis not responding to disease modifying anti-rheumatic drugs (DMARD) received intravenous infliximab at a dose of $3 \mathrm{mg} / \mathrm{kg}$ at baseline and after two and six weeks, and subsequently bimonthly, in combination with methotrexate. Serum samples were collected at baseline and at week 24. A commercial enzyme linked immunosorbent assay was used to test for anti-CCP antibodies; RF were detected using a quantitative nephelometric assay.

Results: At baseline, 38 of the 43 patients (88\%) were positive for anti-CCP antibodies, and 41 (95\%) were positive for RF. The serum titre of anti-CCP and RF decreased significantly after six months of treatment $(p=0.0001$ and $p<0.0001$, respectively). When the patients were grouped on the basis of their clinical response to infliximab, a significant decrease in serum anti-CCP antibodies and RF was observed only in patients who had clinical improvement (ACR 20 and ACR 50).

Conclusions: Anti-TNF $\alpha$ treatment in rheumatoid arthritis results in a decrease in the serum titres of RF and anti-CCP antibodies in patients showing clinical improvement, suggesting that these measurements may be a useful adjunct in assessing treatment efficacy.
\end{abstract}

R heumatoid arthritis is a polyarticular chronic inflammatory disease characterised by synovial pannus formation leading to cartilage destruction and bone erosion. Over the last decade, elucidation of the pathogenic mechanisms driving synovial inflammation and tissue damage in this disease, in particular over the key role of pro-inflammatory cytokines such as tumour necrosis factor $\alpha$ (TNF $\alpha)$ and interleukin 1 (IL-1), has led to the development and clinical use of biological agents that bind to and inactivate these cytokines. In particular, treatment with infliximab-an antiTNF $\alpha$ monoclonal antibody - often results in high clinical efficacy, delay in radiological progression, decrease in serum $\mathrm{C}$ reactive protein, and downregulation of inflammatory cytokines stimulated by TNF $\alpha^{1-4}$ However, despite an impressive overall clinical impact, more than one quarter of patients still have a poor response to these biological agents on the basis of both clinical and radiological evaluation. ${ }^{5}$ So far, no reliable indices have been identified as possible predictive factors for the clinical response in patients undergoing treatment with infliximab. In addition, as up to $40 \%$ of patients with rheumatoid arthritis experience progression towards an erosive pattern in the early stages of the disease, ${ }^{6}$ early diagnosis is crucial so that aggressive treatment can be initiated to delay major articular damage and preserve joint function.

Together with the classical clinical features of the disease, serological abnormalities such as the presence of rheumatoid factors (RF) and, more recently, anti-cyclic citrullinated peptide antibodies (anti-CCP) have been shown to be useful diagnostic tools-particularly in the early stages of the disease-and to be predictive of disease progression and radiological damage..$^{7-10}$ In particular, anti-CCP seem to possess a strong specificity for rheumatoid arthritis, though this was accompanied by a relatively poor sensitivity using the first generation anti-CCP test (anti-CCP1). ${ }^{71}$ However, the currently available so called second generation anti-CCP test (anti-CCP2) has been shown to retain a high specificity for rheumatoid arthritis accompanied by a reasonable $(\sim 80 \%)$ sensitivity. ${ }^{12-14}$

Nevertheless, no data are actually available regarding variations in the titre of anti-CCP during treatment with biological agents such as anti-TNF $\alpha$, and no study has focused on RF modification during infliximab treatment. In this study we measured anti-CCP and RF at baseline and after six months in patients undergoing infliximab treatment. A complete clinical and laboratory evaluation of indices of disease activity was also assessed before and after treatment.

\section{METHODS}

\section{Patients and samples}

Forty three patients ( 35 female and eight male, median age 57 years, range 27 to 78 ) meeting the American College of Rheumatology (ACR) criteria for rheumatoid arthritis ${ }^{15}$ were enrolled in the study. Patients were seen at the division of rheumatology, Università La Sapienza (Rome), at the rheumatology and clinical immunology unit, Brescia Hospital (Brescia), and at the department of rheumatology, G Pini Hospital (Milan). All patients had a history of failed treatment with at least one disease modifying antirheumatic drug (DMARD). Patients were allowed to continue DMARDs, steroids, and non-steroidal anti-inflammatory drugs at a stable dose for at least four weeks before and during infliximab treatment. Patients received infliximab at a dose

Abbreviations: ACR, American College of Rheumatology; CCP, cyclic citrullinated peptide; DMARD, disease modifying antirheumatic drug; $\mathrm{HCV}$, hepatitis $\mathrm{C}$ virus; RF, rheumatoid factor 
of $3 \mathrm{mg} / \mathrm{kg}$ at baseline and after two and six weeks, and subsequently bimonthly. Methotrexate was given in a dose of 10 to $20 \mathrm{mg}$ weekly. In addition to methotrexate, hydroxychloroquine (200 to $400 \mathrm{mg}$ daily) and steroids (maximum daily dose $10 \mathrm{mg}$ of oral prednisone or equivalent) were also permitted.

After obtaining informed consent, we collected blood serum samples from all patients at baseline and after six months of anti-TNF $\alpha$ treatment. The sera were stored at $-20^{\circ} \mathrm{C}$ until assayed.

\section{Clinical and laboratory assessments}

The main clinical and laboratory variables assessed were the erythrocyte sedimentation rate (ESR), $\mathrm{C}$ reactive protein, tender and swollen joint count, patient's assessment of pain, patient's assessment of disease activity, physician's global assessment of disease activity, and the health assessment questionnaire (HAQ). These variables were evaluated at baseline and after six months of anti-TNF $\alpha$ treatment. The ACR response to therapy ${ }^{16}$ was also recorded before and after six months of treatment.

\section{Anti-CCP and RF}

All the serological determinations were centralised in Rome, at the rheumatology department of the Università La Sapienza.

Anti-CCP antibodies were detected using a commercial anti-CCP2 enzyme linked immunosorbent assay kit (Axis Shield, Dundee, UK), following the manufacturer's instructions. Briefly, microtitre plates were incubated for 60 minutes at room temperature with serum samples diluted at 1:100 in phosphate buffered saline. Prediluted anti-CCP standards and positive and negative controls were added to each plate. All assays were done in duplicate. After three washes, plates were incubated for 30 minutes at room temperature with alkaline phosphatase labelled murine monoclonal antibody to human IgG. After three further washes, the enzyme reaction was developed for 30 minutes, stopped with sodium hydroxide-EDTA-carbonate buffer, and the plates read at $550 \mathrm{~nm}$ wavelength. Anti-CCP were considered positive when the absorbance value was higher than the cut off of the kit $(5 \mathrm{U} / \mathrm{ml})$. The concentration of anti-CCP autoantibody was estimated by interpolation from a dose-response curve based on standards.

RF was assayed using quantitative immunonephelometry test (Behring, Marburg, Germany). RF was considered positive when the concentration was higher than the cut off value of the kit $(15 \mathrm{IU} / \mathrm{ml})$.

All serum samples with high concentrations of RF or antiCCP antibodies were further quantified at a greater sample dilution.

To verify the specificity of our assays, we tested for antiCCP antibodies and RF sera from 30 normal human blood donors and 37 patients with hepatitis $\mathrm{C}$ virus (HCV).

\section{Statistical analysis}

The $\chi^{2}$ test was used for testing the significance of differences in baseline autoantibodies. Differences between groups were analysed using the Mann-Whitney $U$ test, and analysis for matched pairs was done with Wilcoxon's signed rank test. To assess whether the variation in anti-CCP and RF correlated with variation in the laboratory and clinical indices incorporated in the ACR criteria for clinical response to treatment, differences in each variable before and after treatment were expressed as a percentage of the baseline value, and correlation analysis was carried out using the Spearman test. A probability (p) value of $<0.05$ was considered significant.

\section{RESULTS}

\section{Clinical response}

Changes in the main clinical and laboratory indices during infliximab treatment are given in table 1. After six months, 22 of 43 patients $(51 \%), 13$ of $43(30 \%)$, and four of $43(9.3 \%)$ fulfilled the ACR $20 \%, 50 \%$, and $70 \%$ criteria for clinical response, respectively. Although a decrease in both ESR (from 42 to $32 \mathrm{~mm} / \mathrm{h}$ ) and C reactive protein (from 24 to $18 \mathrm{mg} / \mathrm{l}$ ) was observed after treatment, the differences were not statistically significant.

\section{Anti-CCP antibodies and RF}

At baseline, 38 of the 43 patients with rheumatoid arthritis $(88 \%)$ were positive for anti-CCP antibodies, and 41 of 43 (95\%) were positive for RF. A strong correlation between anti-CCP and RF at baseline was observed $\left(\chi^{2}, p=0.003\right.$; Spearman, $p=0.006)$. None of the $37 \mathrm{HCV}$ patients or the 30 normal human donors was positive for anti-CCP antibodies, while RF were detected in six of the $37 \mathrm{HCV}$ patients (16\%). No clinical differences at baseline were observed among the patients according to whether they were positive or negative for anti-CCP or RF.

\section{Anti-CCP antibodies and RF variation during infliximab treatment}

Though no patients who were positive for anti-CCP or RF at baseline became negative following the anti-TNF $\alpha$ treatment, the serum titre of anti-CCP antibodies and RF decreased significantly after six months of treatment $(p=0.0001$ and $\mathrm{p}<0.0001$, respectively) (table 1 ). When we grouped the patients on the basis of their clinical response to infliximab, a significant decrease in serum levels of anti-CCP antibodies and RF was observed only in those who were clinically improved according to ACR 20 and ACR 50 criteria (table 2); no significant change in anti-CCP values was observed in patients treated with methotrexate alone (data not shown). It is likely that the ACR70 group was too small to show any significant change in anti-CCP or RF. In addition, we could show that variation in anti-CCP was positively correlated with variation in the tender joint count $(\mathrm{p}<0.02, r=0.42)$, while no correlation was found with the other indices. We did not find any correlation between variation in RF and variation in clinical and laboratory indices after treatment.

When grouping patients with rheumatoid arthritis according to ACR response at six months, the anti-CCP titre at baseline showed a progressive reduction, with higher levels in patients who did not respond to ACR criteria, and progressively lower titres in those who met ACR 20, ACR 50, and ACR 70 responses (fig 1A), although these differences did not reach statistical significance. On the other hand, we did not observe any significant difference between RF serum levels at baseline in the different groups (fig 1B).

Table 1 Main clinical characteristic of patients with rheumatoid arthritis at baseline and after 24 weeks of infliximab treatment

\begin{tabular}{llll}
\hline Variable & Week 0 & Week 24 & p Value \\
\hline Tender joint count (0-44) & $15(2$ to 44$)$ & $10(0$ to 44$)$ & $<0.0001$ \\
Swollen joint count (0-44) & $10(0$ to 30) & $4(0$ to 27$)$ & $<0.0001$ \\
ESR (mm/h) & $42(18)$ & $32(21)$ & NS \\
C reactive protein (mg/l) & $24(21)$ & $18(28)$ & NS \\
Anti-CCP (IU) & $107(9.5)$ & $92(9.8)$ & 0.0001 \\
RF (IU) & $512(151)$ & $409(166)$ & $<0.0001$ \\
\hline
\end{tabular}

Values are mean and range or mean (SD). $C C P$, cyclic citrullinated peptide; ESR, erythrocyte sedimentation rate; RF, rheumatoid factor. 
Table 2 Statistical evaluation of decrease in anti-CCP and RF serum levels in patients with rheumatoid arthritis in relation to clinical improvement after infliximab treatment

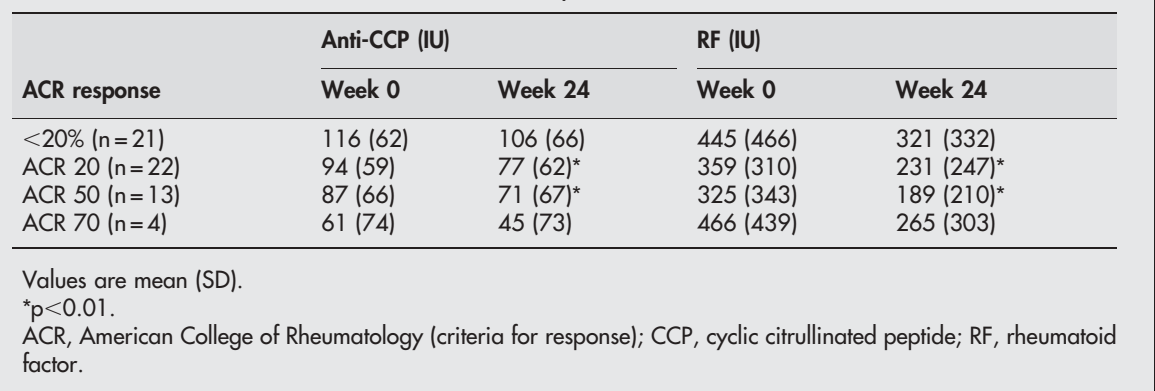

\section{DISCUSSION}

The so called anti-filaggrin antibodies (AFA) represent a group of rheumatoid arthritis specific antibodies originally described in 1964 as "anti-perinuclear factor" (APF) ${ }^{17}$ and in 1979 as anti-keratin antibodies. ${ }^{18}$ These antibodies where subsequently shown to be directed against the epithelial intermediate filament associated protein filaggrin, ${ }^{19}$ which is involved in the aggregation of cytokeratin filaments during cornification of the epidermis. It has recently been shown that filaggrin citrullination is an essential step in its immunogenicity, ${ }^{20}{ }^{21}$ and cyclic citrullinated peptides were subsequently used as antigens in ELISA testing to detect antiCCP antibodies, leading to the generation of the current antiCCP tests. Since the first development of the ELISA for
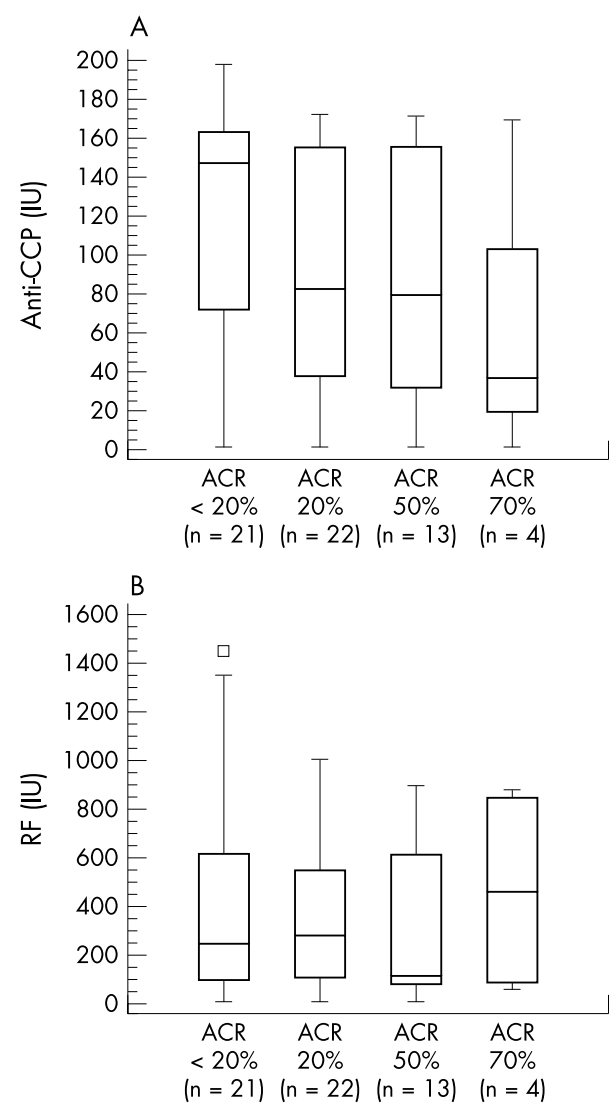

Figure 1 (A) Box and whisker plot of anti-cyclic citrullinated peptide (CCP) serum levels at baseline, classified according to American College of Rheumatology (ACR) response rate after infliximab treatment. Median, quartiles, and ranges are shown. (B) Box and whisker plot of rheumatoid factor (RF) serum levels at baseline, classified according to ACR response rate after infliximab treatment. Median, quartiles, ranges, and a possibly extreme value are shown.
anti-CCP, these antibodies have shown a high specificity (96$98 \%$ ) and a reasonable sensitivity for the diagnosis of rheumatoid arthritis $(60-75 \%$ for anti-CCPI and $\sim 80 \%$ for the second generation anti-CCP2 test). ${ }^{7-14} 20$

Anti-CCP have been found in the early phases of rheumatoid arthritis, ${ }^{82}$ with a significantly greater prevalence in sera of patients who subsequently develop more severe radiological damage. ${ }^{7-10}$ Recently, Visser et al described a clinical prediction model which includes evaluation of antiCCP antibodies, and can discriminate between self limiting, persistent non-erosive, and persistent erosive arthritis. ${ }^{23}$ The role of anti-CCP as an early predictor for identifying patients at risk of more aggressive and erosive disease might be of great importance as it has been suggested that early and aggressive treatment-even with the use of biological agents-can prevent the progression of joint damage. ${ }^{5}$

In this study we showed a significant decrease in the titre of anti-CCP and RF in sera of the patients after 24 weeks of anti-TNF $\alpha$ treatment with infliximab. While a reduction in RF after infliximab has already been described, though in a small subgroup of patients, ${ }^{24}$ this is the first evidence of downregulation of anti-CCP following anti-TNF treatment. The relatively high prevalence of patients who were positive for anti-CCP and RF at baseline in our study (88\% and 95\%, respectively) reflects the probable selection of patients with more aggressive disease, who were resistant to previous DMARD treatment and were eligible for anti-TNF $\alpha$. This provides indirect confirmation of the association between anti-CCP and a more severe disease course.

Although none of the patients who were positive for RF and anti-CCP at baseline became negative during follow up, we observed a significant decrease in the titre of these autoantibodies after six months of treatment with infliximab. The importance of this observation is strengthened by evidence that a significant decrease in the titre of these autoantibodies occurs only in patients who are clinically improved after six months of treatment with infliximab. Moreover, we were able to show that variation in anti-CCP levels after treatment was positively correlated with variation in the tender joint count. Thus, modification of serum antiCCP seems to parallel the improvement in clinical and laboratory variables observed during treatment with infliximab. Furthermore, the importance of a quantitative evaluation of anti-CCP is suggested by our observation that lower levels of anti-CCP antibodies at baseline seemed to predict a better clinical response after six months of treatment with infliximab. This observation needs confirmation in larger studies, but is of particular importance because, in contrast to Crohn's disease, ${ }^{25} 26$ no predictor of clinical response to infliximab has as yet been identified.

While no data are currently available on the prognostic importance of a quantitative evaluation of anti-CCP levels in patients with rheumatoid arthritis, it has been shown that a high titre $(>1: 160)$ of $\mathrm{RF}$ at baseline is an independent 
predictor of deteriorating radiographic damage after five years from the time of presentation. ${ }^{27}$ Thus our findings suggest that serial evaluation of these antibodies could be useful in monitoring the clinical course of the disease, at least in patients undergoing treatment with infliximab. Nevertheless, this study is relatively short term, with a follow up limited to 24 weeks, and further studies in a larger cohort of patients and with longer follow up are needed to determine the prognostic value of anti-CCP antibodies and $\mathrm{RF}$ in patients treated with infliximab (in relation to both clinical and radiological progression).

The mechanisms whereby blocking of TNF $\alpha$ by infliximab could lead to a decrease in the generation of autoantibodies such as anti-CCP and RF are not understood, and explanation of this phenomenon remains speculative. However, it has been shown that infliximab can downregulate the production of several inflammatory cytokines and mediators, ${ }^{48}$ and these anti-inflammatory effects may account for the reduction in autoantibody generation, particularly in the synovial compartment.

It has also been shown that citrullination represents a posttranslational modification of proteins in the apoptotic process, ${ }^{29}$ and that citrullinated fibrin is one of the major citrullinated proteins in rheumatoid synovium, and so represents an important antigenic target of anti-filaggrin antibodies. ${ }^{30}$ It has been found that anti-TNF $\alpha$ treatment can modulate apoptotic processes, as recently shown in inflammatory bowel disease, ${ }^{31}$ so it is possible that regulation of apoptosis following $\mathrm{TNF} \alpha$ blockade could partially explain our observation. However, further studies are needed to determine whether changes in serum levels of anti-CCP during infliximab treatment are related to modulation of apoptotic cell death.

\section{Conclusions}

Our results suggest that evaluation of anti-CCP antibodies and rheumatoid factor may be useful in clinical practice, not only as a diagnostic tool but also for predicting possible clinical improvement with anti-TNF $\alpha$ therapy.

\section{Authors' affiliations}

C Alessandri, M Bombardieri, L Magrini, G Valesini, Cattedra di Reumatologia, Dipartimento di Clinica e Terapia Medica Applicata, Università "La Sapienza", Rome, Italy

N Papa, Dipartimento di Reumatologia, Istituto Ortopedico G Pini, Milan, Italy

M Cinquini, A Tincani, Servizio di Immunologia Clinica e Reumatologia, Ospedali Civili, Brescia, Italy

\section{REFERENCES}

1 Maini RN, Taylor PC. Anti-cyłokine therapy for rheumatoid arthritis. Annu Rev Med 2000:51:207-29.

2 Maini RN, St Clair EW, Breedveld F, Furst D, Kalden J, Weisman M, et al. Infliximab (chimeric anti-tumour necrosis factor alpha monoclonal antibody) versus placebo in rheumatoid arthritis patients receiving concomitant methotrexate: a randomised phase III trial. Lancet 1999;354:1932-9.

3 Charles P, Elliott MJ, Davis D, Potter A, Kalden JR, Antoni C, et al. Regulation of cytokines, cytokine inhibitors, and acute-phase proteins following anti-TNFalpha therapy in rheumatoid arthritis. J Immunol 1999;163:1521-8.

4 Pittoni V, Bombardieri M, Spinelli FR, Scrivo R, Alessandri C, Conti F, et al. Anti-tumour necrosis factor (TNF) alpha treatment of rheumatoid arthritis (infliximab) selectively down regulates the production of interleukin (IL) 18 but not of IL12 and IL13. Ann Rheum Dis 2002;61:723-5.

5 St Clair EW. Infliximab treatment for rheumatic disease: clinical and radiological efficacy. Ann Rheum Dis 2002;(suppl II):ii67-ii69.

6 Plant MJ, Jones PW, Saklatvala J, Ollier WE, Dawes PT. Patterns of radiological progression in early rheumatoid arthritis: results of an 8 year prospective study. J Rheumatol 1998;25:417-26.

7 Schellekens GA, Visser H, de Jong BA, van den Hoogen FH, Hazes JM, Breedveld FC, et al. The diagnostic properties of rheumatoid arthritis antibodies recognizing a cyclic citrullinated peptide. Arthritis Rheum 2000;43:155-63

8 Kroot EJ, de Jong BA, van Leeuwen MA, Swinkels $H$, van den Hoogen FH, van't Hof $M$, et al. The prognostic value of anti-cyclic citrullinated peptide antibodies in patients with recent-onset rheumatoid arthritis. Arthritis Rheum 2000;43:1831-5.

9 Meyer O, Labarre C, Dougados M, Goupille P, Cantagrel A, Dubois A, et al. Anticitrullinated protein/peptide antibody assays in early rheumatoid arthritis for predicting five year radiographic damage. Ann Rheum Dis 2003;62:120-6.

10 Bas S, Genevay S, Meyer O, Gabay C. Anti-cyclic citrullinated peptide antibodies, $\lg M$ and $\lg A$ rheumatoid factors in the diagnosis and prognosis of rheumatoid arthritis. Rheumatology 2003;42:677-80.

11 Bizzaro N, Mazzanti G, Tonutti E, Villalta D, Tozzoli R. Diagnostic accuracy of the anti-citrulline antibody assay for rheumatoid arthritis. Clin Chem 2001;47:1089-93.

12 Vasishta A. Diagnosing early-onset rheumatoid arthritis: the role of anti-CCP antibodies. Am Clin Lab 2002;21:34-6.

13 van Venrooii WJ, Hazes JM, Visser H. Anticitrullinated protein/peptide antibody and its role in the diagnosis and prognosis of early rheumatoid arthritis. Neth J Med 2002:60:383-8.

14 Vossenaar ER, van Venrooii WJ. Anti-CCP antibodies, a highly specific marker for (early) rheumatoid arthritis. Clin Appl Immunol Rev 2004;4:225-94.

15 Arnett FC, Edworthy SM, Bloch DA, McShane DJ, Fries JF, Cooper NS, et al. The American Rheumatism Association 1987 revised criteria for the classification of rheumatoid arthritis. Arthritis Rheum 1988;31:315-24.

16 Felson DT, Anderson JJ, Boers M, Bombardier C, Chernoff M, Fried B, et al. The American College preliminary core set of disease activity measures for rheumatoid arthritis clinical trials. Arthritis Rheum 1993;36:729-40.

17 Nienhuis RL, Mandema E. A new serum factor in patients with rheumatoid arthritis. The antiperinuclear factor. Ann Rheum Dis 1964;23:302-5.

18 Young BJ, Mallya RK, Leslie RD, Clark CJ, Hamblin TJ. Anti-keratin antibodies in rheumatoid arthritis. BMJ 1979:2:97-9.

19 Sebbag M, Simon M, Vincent C, Masson-Bessiere C, Girbal E, Durieux JJ, Serre G. The antiperinuclear factor and the so-called antikeratin antibodies are the same rheumatoid arthritis-specific autoantibodies. J Clin Invest 1995:95:2672-9.

20 Schellekens GA, de Jong BA, van den Hoogen FH, van de Putte LB, van Venrooij WJ. Citrulline in an essential constituent of antigenic determinants recognized by rheumatoid arthritis-specific autoantibodies. J Clin Invest 1998;101:273-81.

21 Girbal-Neuhauser E, Durieux JJ, Arnaud M, Dalbon P, Sebbag M, Vincent C, et al. The epitopes targeted by the rheumatoid arthritis-associated antifilaggrin autoantibodies are posttranslationally generated on various sites of (pro)filaggrin by deimination of arginine residues. J Immunol 1999; 162:585-94.

22 Jansen AL, van der Horst-Bruinsma I, van Schaardenburg D, van de Stadt RJ, de Koning MH, Dijkmans BA. Rheumatoid factor and antibodies to cyclic citrullinated Peptide differentiate rheumatoid arthritis from undifferentiated polyarthritis in patients with early arthritis. J Rheumatol 2002;29:2074-6.

23 Visser H, le Cessie S, Vos K, Breedveld FC, Hazes JM. How to diagnose Rheumatoid Arthritis early. A prediction model for persistent (erosive) arthritis. Arthritis Rheum 2002;46:357-65.

24 Charles PJ, Smeenk RJ, De Jong J, Feldmann M, Maini RN. Assessment of antibodies to double-stranded DNA induced in rheumatoid arthritis patients following treatment with infliximab, a monoclonal antibody to tumor necrosis factor alpha: findings in open-label and randomised placebo-controlled trials. Arthritis Rheum 2000;43:2383-90.

25 Esters N, Vermeire S, Joossens S, Noman M, Louis E, Belaiche J, et al. Serological markers for prediction of response to anti-tumor necrosis factor treatment in Crohn's disease. Am J Gastroenterol 2002;97:1458-62.

26 Vermeire S, Louis E, Carbonez A, Van Assche G, Noman M, Belaiche J, et al. Demographic and clinical parameters influencing the short-term outcome of anti-tumor necrosis factor (infliximab) treatment in Crohn's disease. Am J Gastroenterol 2002;97:2357-63.

27 Bukhari M, Lunt M, Harrison BJ, Scott DG, Symmons DP, Silman AJ. Rheumatoid factor is the major predictor of increasing severity of radiographic erosions in rheumatoid arthritis: results from the Norfolk Arthritis Register Study, a large inception cohort. Arthritis Rheum 2002;46:906-12.

28 Ziolkowska M, Maslinski W. Laboratory changes on anti-tumor necrosis factor treatment in rheumatoid Arthritis. Curr Opin Rheumatol 2003; 15:267-73.

29 Inagaki M, Takahara H, Nishi Y, Sugawara K, Sato C. Ca ${ }^{2+}$-dependent deimination induced disassembly of intermediate filaments involves specific modification of the amino-terminal head domain. J Biol Chem 1989;264:18119-27.

30 Masson-Bessiere C, Sebbag M, Girbal-Neuhauser E, Nogueira L, Vincent C, Senshu $T$, et al. The major synovial targets of the rheumatoid arthritis-specific antifilaggrin autoantibodies are deiminated forms of the alpha and betachains of fibrin. J Immunol 2001;166:4177-84.

31 Lugering A, Schmidt M, Lugering N, Pauels HG, Domschke W, Kucharzik T. Infliximab induces apoptosis in monocytes from patients with chronic active Crohn's disease by using a caspase-dependent pathway. Gastroenterology 2001;121:1145-57. 